\title{
Enzymatic biosensor associated with Molecularly Imprinted Polymers for sensitive and selective detection of organophosphorus insecticides in olive oil
}

\author{
Ben Oujji Najwa ${ }^{1,2}$, Bakas Idriss ${ }^{1,2}$, Istamboulie Georges ${ }^{1}$, Ait-Ichou Ihya ${ }^{2}$, Ait-Addi Elhabib ${ }^{2}$, \\ Rouillon Régis ${ }^{1}$, Noguer Thierry ${ }^{1}$ \\ ${ }^{1}$ University of Perpignan, IMAGES EA4218, Building S 52 Av Paul Alduy, 66860 Perpignan Cedex, France \\ ${ }^{2}$ University Ibn Zohr, AQUAMAR, Photocatalysis and Environment Team, Chemistry Department/Faculty of Science, BP 8106 Citè Dakhla, \\ Agadir, Morocco
}

\section{Email address:}

najwa_benoujji@hotmail.com (N. Ben oujji),najwabenoujji@gmail.com (N. Ben oujji)

\section{To cite this article:}

Ben Oujji Najwa, Bakas Idriss, Istamboulie Georges, Ait-Ichou Ihya, Ait-Addi Elhabib, Rouillon Régis, Noguer Thierry. Enzymatic Biosensor Associated with Molecularly Imprinted Polymers for Sensitive and Selective Detection of Organophosphorus Insecticides in Olive Oil. Science Innovation. Special Issue: Biosensors: Innovative Technique for Food Safety and Environmental Monitoring. Vol. 2, No. 6-1, 2014, pp. 1-6. doi: 10.11648/j.si.s.2014020601.11

\begin{abstract}
: 5 different bio-tools have been developed for sensitive detection of three organophosphorus insecticides mainly used for the treatment of olive trees: Malaoxon, Omethoate and Methidathion-oxon. The systems are based on the immobilization of electric eel acetylcholinesterase on screen-printed electrode (SPE) and microtiter plates by 3 different methods of immobilization. These developed systems were optimized with laboratory samples and then tested on natural samples of olive oil after a simple liquid-liquid extraction. Among these five systems designed, the amperometric biosensor based on acetylcholinesterase immobilized by bioencapsulation in a sol-gel matrix presented the best performance in terms of operational stability, storage stability, reproducibility, and it proved to be best suited for the determination of insecticides in real samples of olive oil. This biosensor has been associated with a highly selective extraction method based on the use of Molecularly Imprinted Polymers (MIPs) to improve selectivity. The results showed that the association MIPs-biosensor can selectively detect and quantify the three organophosphorus insecticides in such a complex matrix as olive oil, with limits of detection much lower than the maximum residue limit tolerated by international regulations.
\end{abstract}

Keywords: Organophosphorus Insecticides, Electric Eel Acetylcholinesterase, Molecularly Imprinted Polymer (MIP), Biosensors, Olive Oil

\section{Introduction}

Olive oil is the principal source of lipids in the Mediterranean diet, and its consumption in the world is increasing due to related potential health benefits, such as a lower incidence of cardiovascular diseases, neurological disorders, breast and colon cancers, as well as its hypolipidemic and antioxidant properties [1]. Beside relevant advances in production, there are some serious problems caused by different insects which attack and damage olive trees. One of them is the common olive oil fruit fly Bactrocera oleae, which induces an increase of acidity, affects fruits shelf life and decreases the yield of the olives. In order to protect trees from the infection and avoid significant losses in olive oil production, trees are usually treated with suitable pesticides which act as repellents against flies or other insects [2]

The most extensively used agrochemicals in the cultivation of olives are organophosphorus insecticides [3] and they are mainly Fenthion, Dimethoate, Diazinon, Parathion-methyl, Methidathion, Azinphos-ethyl, and Malathion [4]. These biochemicals provide accurate, rapid and cost-effective treatment but become dangerous if applied at the harvest stage. The consumption of the contaminated olives may present a high risk for human health. Additionally, the majority of these pesticides are lipophilic and are able to remain in the oil for extended periods of time [5]. The development of accurate methods for the determination of pesticide residues in olives is therefore necessary to ensure the production of reliable quality olive oil for the consumers health and confidence [6]. 
Among the many methods reported for pesticides detection, chromatographic methods such as HPLC and GC are often used as reference methods. Despite their high sensitivities, these techniques are expensive, time-consuming and require highly trained personnel. Additionally, analytical problems associated with the analysis of pesticides in fatty foods, such as olive oil, are well known, especially when common GC analysis is applied, even small amount of lipids can harm columns, detectors or cause signal suppression [7].
Biochemical sensors could be a reliable and promising alternative to these classical methods because of their simplicity, ease of use, and high sensitivity and selectivity [8].

We have described in a previous works the development of different bio-tools for the sensitive detection of three organophosphorus insecticides in olive oil: Malathion, Dimethoate and Methidathion, in their oxidized forms (Figure 1).

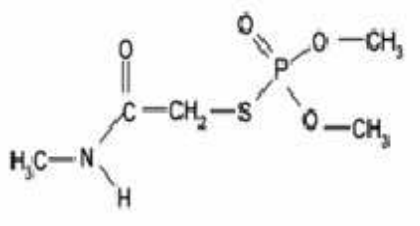

(a)

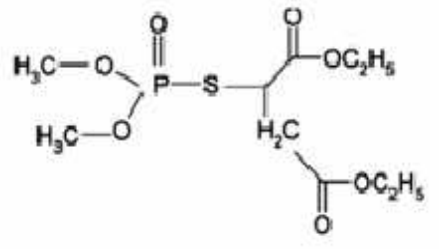

(b)

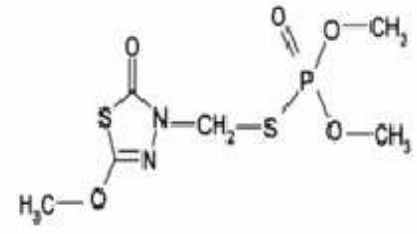

(c)

Figure 1. Chemical structures of OPs insecticides used in oleiculture; (a) Omethoate, (b) Malaoxon and (c) Methidathion-oxon.

The developed systems are bioassays based on optical detection or biosensors based on amperometric measurements. The enzyme used as bioreceptor was the electric eel acetylcholinesterase (AChE-EE). Three immobilization methods have been tested: immobilization by adsorption [9], covalent immobilization on magnetic beads [10] and immobilisation by entrapment in a sol-gel matrix [11]. Depending on the support used (microplates or screen printed electrodes), 5 different tools have been developed: two optical bioassays and 3 amperometric biosensors. These developed systems were optimized with laboratory samples and then tested on natural samples of olive oil after a simple liquid-liquid extraction. Among these five systems designed, the amperometric biosensor based on acetylcholinesterase immobilized by bioencapsulation in a sol-gel composite presented the best performance in terms of operational stability, storage stability, reproducibility, and it proved to be best suited for the determination of real samples of olive oil, although this biosensor show a high sensitivity, it lack of selectivity due to the fact that it react with any cholinesterase inhibitor. In the literature to resolve a mixture of organophosphorus pesticides with the acetylcholinesterase biosensors is possible using a combined recognition / discrimination strategy based on the joint action of acetylcholinesterase and phosphotriesterase $[12 ; 13]$ and the use of Artificial Neural Networks (ANNs) as a chemometric data analysis tool $[14 ; 15]$. In these studies different types of acetylcholinesterase were used, the most common are genetically modified enzymes which are less available on the market and complicated to use. The aim of this work was to improve the selectivity of the previously described sensor, without increasing the cost and the complexity of the system, by combining the selected biosensor with a sample preconcentration based on Solid-Phase Extraction (SPE) cartridge packed with polymers imprinted with Omethoate, Malaoxon or Methidathion-oxon.

Molecularly imprinted polymers (MIPs) are a class of highly cross-linked polymer that can bind certain target compound with high specificity [16]; they possess several advantages over the conventional immunosorbent (IS). They show high selectivity and affinity, high stability and the ease of preparation [17]. The MISPE is a current trends for the control of the pollutant which already been successfully applied for the pre-concentration and trace detection of various analyte in environmental, clinical or food samples including olive oil $[18 ; 19 ; 20]$.

The molecular imprinted polymers used in this study were specially designed for the three targets pesticides [18; 19]. The results showed that combination of biosensor with molecularly imprinted polymer (MIPs) allows sensitive and selective detection of the three pesticides in a complex matrix such as olive oil, with limits of detection much lower than the maximum residue limit tolerated by international regulations. To our knowledge, this is the first paper describing the association of MIPs and biosensor for the determination of organophosphorus insecticide in such a complex matrix as olive oil.

\section{Materials and Methods}

\subsection{Chemicals and Stock Solutions}

AChE (EC 3.1.1.7) from electric eel (EE) (Type V-S, 1,000 $\mathrm{U} / \mathrm{mg}$ ) was purchased from Sigma-Aldrich (St Quentin-Fallavier, France). Acetylthiocholine chloride (ATChCl), and 5,5-dithiobis(2-nitrobenzoic acid) (DTNB-Ellman's reagent) were provided by Sigma. In order to minimize hydrolysis, ATChCl solution was prepared daily in $0.9 \% \mathrm{NaCl}$ (Sigma-Aldrich) solution. Stock solutions of enzymes and DTNB were prepared in $0.1 \mathrm{M}$ phosphate buffer $\left(\mathrm{Na}_{2} \mathrm{HPO}_{4} / \mathrm{KH}_{2} \mathrm{PO}_{4}\right.$, Sigma-Aldrich) at $\mathrm{pH}$ 7. The organophosphorus insecticides Malaoxon, Omethoate and Methidathion were purchased from Dr. Ehrenstorfer (Augsburg, Germany). Pesticide stock solutions (concentration $10^{-3} \mathrm{M}$ ) were prepared in acetonitrile (Sigma) and stored at $4{ }^{\circ} \mathrm{C}$, working pesticide solutions were prepared 
daily in distilled water by dilution of the stock solution. The oxidation of Methidathion was achieved using N-bromosuccinimide (NBS) provided by Sigma-Aldrich. Hexane, dichloromethane and methanol were purchased from Sigma-Aldrich (France). Sol-gel matrices were prepared using tetramethoxysilane (TMOS), poly(ethyleneglycol) 600 (PEG), hydroxyethyl-cellulose (HEC) (Sigma-Aldrich) and hydrochloric acid ( $\mathrm{HCl})$ (Carlo Erba, Italy). Graphite (Electrodag 423SS) and silver/silver chloride (Electrodag 418SS) inks were obtained from Acheson (Plymouth, UK). Cobalt

Phtalocyanine modified carbon paste was purchased from Gwent Electronic Materials, Ltd. (Gwent, UK). Poly(vinyl)chloride (PVC) sheets $(200 \mathrm{~mm} \times 100 \mathrm{~mm} \times 0.5$ $\mathrm{mm}$ ), supplied by SKK (Denzlingen, Germany), were used as support for the screen-printed electrodes. A glycerophtalic paint (Astral, France) was used as insulating layer.

\subsection{Apparatus}

The determination of AChE activity was carried out with a Hewlett Packard diode array 8451A spectrophotometer and the AChE activities were measured spectrophotometrically as described by Ellman [20]. Amperometric measurements were carried out with a 641VA potentiostat (Metrohm, Switzerland), which imposed a constant potential of $100 \mathrm{mV}$ between screen-printed working and reference $(\mathrm{Ag} / \mathrm{AgCl})$ electrodes. The current was measured with a BD40 (Kipp \& Zonen, The Netherlands) flatbed recorder. Screen-printed electrodes were produced using a semi-automatic DEK248 printing machine according to a procedure previously described by Andreescu et al.,[8], but in a three-electrode configuration. The working electrode was a $4 \mathrm{~mm}$-diameter disk, the auxiliary electrode was a $16 \mathrm{~mm} \times 1.5 \mathrm{~mm}$ curved line and the $\mathrm{Ag} / \mathrm{AgCl}$ pseudo-reference electrode was a $5 \mathrm{~mm} \times 1.5 \mathrm{~mm}$ straight track. Chromatographic measurements were performed using an HPLC L-2000 series LaChrom Elite ${ }^{\circledR}$ system from Merck-Hitachi (VWR, France).

\subsection{Biosensor Manufacturing (Ben Oujji et al., 2013)}

$3 \mathrm{mIU}$ of electric eel acetylcholinesterase was immobilized on screen printed electrodes (SPE) by bioencapsulation in a sol gel composite. The protocol of immobilization was the following: the sol-gel solution was prepared by mixing $150 \mu \mathrm{L}$ of the precursor tetramethoxysilane (TMOS) with $413 \mu \mathrm{L}$ of distilled water, $400 \mu \mathrm{L}$ of $\mathrm{HCl} 1 \mathrm{mM}$, and $37 \mu \mathrm{L}$ of PEG 600 . This mixture was sonicated for $15 \mathrm{~min}$ and stored for one night at $4{ }^{\circ} \mathrm{C}$. The enzymatic solution prepared in phosphate buffer $(\mathrm{pH})$ was mixed $1: 1(\mathrm{v} / \mathrm{v})$ with HEC $(2 \%)$. Then, this solution was mixed with the sol-gel in a ratio $2: 1(\mathrm{v} / \mathrm{v})[22] .2$ $\mu \mathrm{L}$ of the obtained solution was quickly deposited on the surface of the working electrode, and allowed to dry for $3 \mathrm{~h}$ at room temperature.

\subsection{Amperometric Measurements}

The screen-printed electrode system, with the enzyme immobilized, was vertically immersed in a thermostated cell $\left(30^{\circ} \mathrm{C}\right)$ containing $10 \mathrm{~mL}$ phosphate buffer $\mathrm{pH} 7$ under constant magnetic stirring $(250 \mathrm{rpm})$ as shown in figure 2 . The applied potential was $100 \mathrm{mV}$ vs $\mathrm{Ag} / \mathrm{AgCl}$ reference electrode, using cobalt phtalocyanine as mediator. The current intensity was recorded and, after current stabilization, the substrate ATCh was added to the cell, so that the final concentration was $1 \mathrm{mM}$. The measured signal corresponded to the difference of current intensity between the baseline and the plateau. The cell was washed with distilled water between measurements.

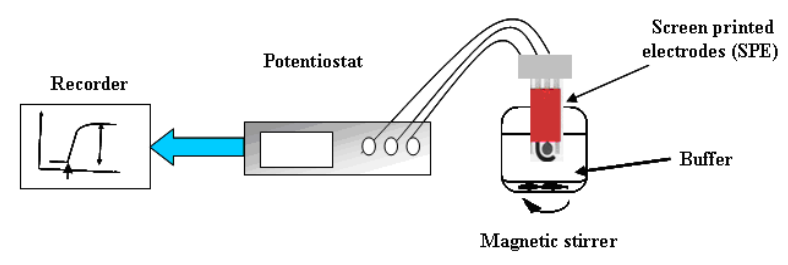

Figure 2. Setup used for the amperometric measurements.

The pesticide detection was made in a three-step procedure as follows: the initial response of the biosensor to $1 \mathrm{mM}$ ATCh was recorded three times, then the electrode was incubated for $10 \mathrm{~min}$ in a solution containing a known concentration of insecticide extracted using MISPE, and finally the residual response of the electrode was recorded again. Electrodes were thoroughly washed with distilled water between each measurement. The percentage of the inhibition was correlated with the insecticide concentration; the inhibition rate was calculated according to the following formula:

I $(\%)=\left[\left(\mathrm{I}_{0}-\mathrm{I}\right) / \mathrm{I}_{0}\right] 100, \mathrm{I}$ and $\mathrm{I}_{0}$ being respectively the current after the and before inhibition.

\subsection{Olive Oil Analysis}

Before assays, the pesticides were extracted using MIPs as follows: $10 \mathrm{ml}$ of a commercially available extra virgin olive oil purchased in a local supermarket was spiked with known concentration of pesticide prepared in hexane. The mixture was incubated at $45^{\circ} \mathrm{C}$ for $30 \mathrm{~min}$ while stirring. Then $1 \mathrm{~mL}$ of this oil was diluted in $9 \mathrm{~mL}$ of hexane and passed through SPE cartridges containing imprinted polymer previously conditioned with $5 \mathrm{~mL}$ of hexane. The cartridges were washed with $5 \mathrm{~mL}$ of hexane containing $20 \%$ dichloromethane and eluted with $1 \mathrm{~mL}$ of methanol. This fraction was then evaporated to dryness, reconstituted in $10 \mathrm{~mL}$ of phosphate buffer $\mathrm{pH} 7$ and directly analyzed by the amperometric biosensor as described previously. The viability of this extraction technique was verified by chromatographic tests (HPLC-UV), showing a good efficiency of this extraction protocol with $100 \pm 1.4 \%$ of recovery percentage.

\section{Results and Discussion}

\subsection{Biosensors Characterizations}

The previously described biosensors (Ben oujji et al., 2013) presented a good operational stability as they maintained their initial analytical signal response during 10 successive measurements. The electrodes response for successive 
substrate injection was $450 \mathrm{nA} \pm 15 \mathrm{nA}$ for 10 assays, indicating a good reproducibility of measurements. Inhibition reproducibility experiments were carried out by measuring 5 times the inhibition percentage produced by $10^{-8} \mathrm{M}$ of Malaoxon, the obtained results showed a good reproducibility of the developed device with a relative standard deviation (R.S.D) of 3\% (324 $\pm 10 \mathrm{nA})$. Concerning storage stability, no loss of activity was observed after 1 month storage at $-18^{\circ} \mathrm{C}$, providing that the electrodes were kept in sealed plastic bags. The analytical performance of the developed device is presented on Table 1.

The results showed a good analytical performance of the developed tools with reasonable limits of detection, as low as $10^{-9} \mathrm{M}$ for Malaoxon, $10^{-8} \mathrm{M}$ for Methidathion-oxon and $10^{-7} \mathrm{M}$ for Omethoate. The application on the spiked olive oil samples showed a good correlation with the results produced by standards solutions with almost $100 \%$ of recovery percentage for all the pesticides concentration tested, with a Relative Standard Deviation (R.S.D) of $4.7 \%$.

Table 1. Performances of the developed biosensor for the detection of Omethoate, Methidathion-oxon and Malaoxon. LOD (IC 10$), I C_{50}$ and $I C_{0}$ are the concentrations of pesticides inducing respectively $10 \%, 50 \%$ and $0 \%$ decrease of the signal.

\begin{tabular}{lllll}
\hline Pesticide & $\mathbf{I}_{\mathbf{0}}(\mathbf{M})$ & $\mathbf{I}_{\mathbf{1 0}}(\mathbf{M})$ & $\mathbf{I}_{\mathbf{5 0}}(\mathbf{M})$ & $\begin{array}{l}\text { Dynamic range } \\
\left(\mathbf{m o l ~ L} \mathbf{L}^{-\mathbf{1}}\right)\end{array}$ \\
\hline $\begin{array}{l}\text { Omethoate } \\
\text { Methidathion }\end{array}$ & $4.0 \times 10^{-7}$ & $4.3 \times 10^{-7}$ & $1.5 \times 10^{-5}$ & $7.5 \times 10^{-5}-2.5 \times 10^{-6}$ \\
$\begin{array}{l}\text { oxon } \\
\text { Malaoxon }\end{array}$ & $1.3 \times 10^{-8}$ & $2.0 \times 10^{-8}$ & $1.1 \times 10^{-7}$ & $5 \times 10^{-6}-5 \times 10^{-8}$ \\
\hline
\end{tabular}

\subsection{Real Samples Analysis}

Table 2. Solid-Liquid extraction protocol

\begin{tabular}{lll}
\hline Molecularly Imprinted Polymers & Percolation Solution & Washing Solution \\
\hline MIP-Malaoxon & $1 \mathrm{~mL}$ of spiked olive oil +9 & $2 \mathrm{~mL}$ of dichloromethane \\
MIP-Methidathion-oxon & mL of hexane & $2 \mathrm{~mL}(80 \%$ hexane and $20 \%$ dichloromethane). \\
MIP-Omethoate & & $2 \mathrm{~mL}(85 \%$ hexane and $15 \%$ dichloromethane). \\
\hline
\end{tabular}

Before testing the selectivity, the biosensor response to real samples of olive oil spiked with various concentrations of pesticide and extracted using MIPs, as described previously, was tested. A comparison between the inhibition percentages obtained with standard solutions prepared in buffer and real samples of olive oil is shown in Figure 3. The presented results are based on quadruplicate for each concentration of pesticides.

The recovery percentage of insecticides from the spiked samples was almost $100 \%$ for all the pesticides concentration tested, with a Relative Standard Deviation (R.S.D) of 2.3\%, demonstrating the good performance of the developed device for the detection of these pesticides in real samples of olive oil but also the good performance of the extraction method used.

Selectivity tests were carried out using a mixture of the three target molecules using pesticide concentrations inducing $50 \%$ decrease of the sensor signal $\left(\mathrm{IC}_{50}\right): 10 \mathrm{ml}$ of olive oil was doped with $5.10^{-8} \mathrm{M}$ of Malaoxon, $2.5 \times 10^{-7} \mathrm{M}$ of Methidathion-oxon and $2.5 \times 10^{-5} \mathrm{M}$ of Omethoate. The mixture was incubated at $45^{\circ} \mathrm{C}$ for 30 min while stirring, and then $1 \mathrm{ml}$ of this oil was diluted in $9 \mathrm{ml}$ of hexane as described in experimental part. The solution obtained is percolated through a cartridge containing the MIPs synthesised for Omethoate, Malaoxon or Methidathion-oxon. All interfering components, which were present in olive oil, were removed using an appropriate washing solution. The nature and the volume of the washing solvent was optimised for each pesticide, in order to obtained the best specificity and complete recovery. In our case the best results were achieved by using the dichloromethane for Malaoxon or a mixture of dichloromethane and hexane for Omethoate and Methidathion-oxon (Table 2).

Elution was performed using $1 \mathrm{~mL}$ of methanol to get the target molecules; this fraction was evaporated to dryness, reconstituted in $10 \mathrm{~mL}$ of phosphate buffer $\mathrm{pH} 7$ and directly analyzed by the amperometric biosensor. The obtained results are presented in Table 3 .

Table 3. Inhibition rate (\%) obtained with the biosensor, using samples of pesticides extracted with MIPs. Tests were performed in quadruplicate, RSD $<3 \%$.

\begin{tabular}{lll}
\hline \multirow{2}{*}{ MIPs } & $\begin{array}{l}\text { Samples tested: Olive oil } \\
\text { spiked with }\end{array}$ & Inhibition \% \\
\hline \multirow{2}{*}{ MIP-Malaoxon } & Malaoxon only $\left(5.10^{-8} \mathrm{M}\right)$ & $57 \pm 2.94$ \\
\multirow{2}{*}{ MIP-Methidathion } & Mixture of pesticides & $100 \pm 1.25$ \\
oxon & Methidathion only $\left(2.5 \times 10^{-7} \mathrm{M}\right)$ & $66 \pm 0.34$ \\
MIP-Omethoate & Mixture of pesticides & $68 \pm 1.04$ \\
& Omethoate only $\left(2.5 \times 10^{-5} \mathrm{M}\right)$ & $58 \pm 1.28$ \\
& Mixture of pesticides & $61 \pm 2.31$ \\
\hline
\end{tabular}

The results show that the inhibition percentages obtained with olive oil doped with one pesticide are consistent and in a good agreement with the expected results. Using MIPs synthesised for Omethoate or Methidathion-oxon, the samples spiked with a mixture of the 3 target pesticides gave, after extraction, the same inhibition percentage obtained when the olive oil was spiked with a single molecule. Thus, the synthesised MIPs were able to recognise their target molecules, as these molecules fitted well within the imprinted cavity. These results show that the developed MIPs can be used for the selective extraction of Methidathion-oxon and Omethoate from real samples of olive oil. Whereas, when olive oil spiked with mixture of pesticides was extracted using the MIP developed for Malaoxon, a complete inhibition of the sensor was observed. Therefore, this combination MIPs-biosensor allows the sensitive and selective detection of Omethoate and Methidathion-oxon, but not for Malaoxon. Dealing with a mixture of these three compounds, the biosensor can be selective for the Malaoxon if the extraction is done in a three steps procedure, using MIP-Omethoate, MIP-Methidathion and the MIP-malaoxon last. Indeed, the solution issue from these three extractions only contains 
Malaoxon which can easily be detected by the biosensor.
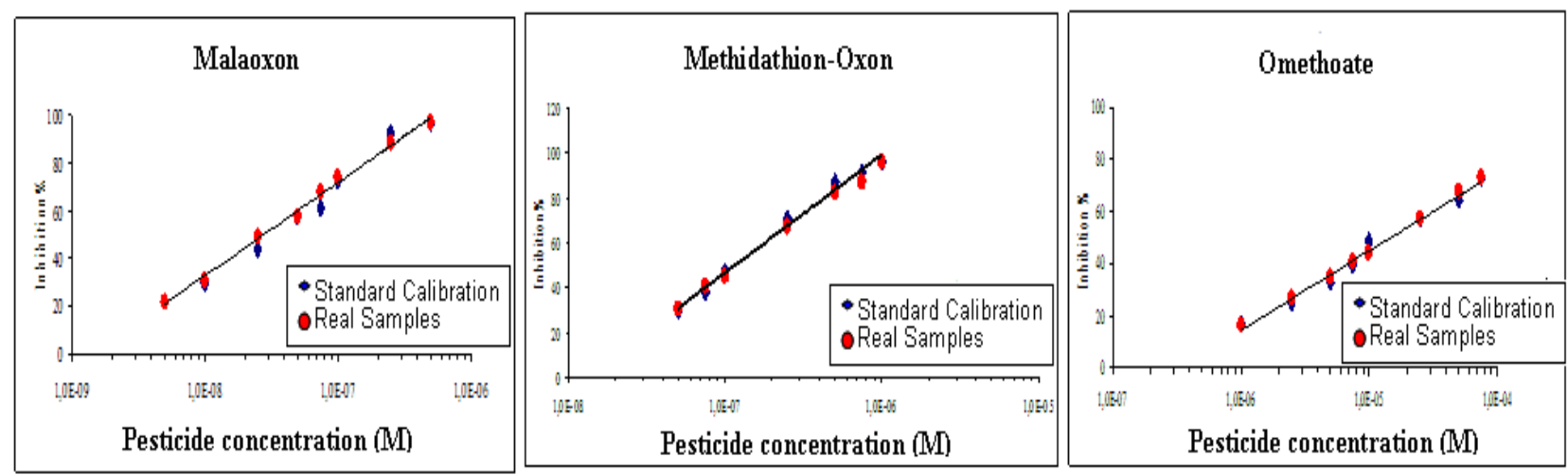

Figure 3. Detection of Omethoate, Methidathion-oxon and Malaoxon in olive oil real samples, comparison with the standard curves.

\section{Conclusions}

The biosensor based on the immobilization of electric eel acetylcholinesterase by bioencapsulation in a sol gel composite on screen printed electrodes fulfils the requirement for simple, rapid and inexpensive monitoring of three organophosphorus insecticides in olive oil. The method requires just 10 minutes and can substitute in many cases more complex analysis. The lack of selectivity of this biosensor can be a disadvantage when the nature of the insecticide used is not identified, or more generally when dealing with mixtures of active substances. This problem can be solved in various ways; such studies have been conducted using complex systems involving several enzymes and the use of Artificial Neural Networks (ANNs) as a chemometric data analysis tool. In this work, we have chose a different approach, coupling the high sensitive detection of the biosensor with a sample pre-concentration based on a SPE cartridge packed with polymers imprinted with Omethoate, Malaoxon or Methidathion-oxon. Therefore, in this paper we show that the combination of the amperometric biosensor and extraction step using molecularly imprinted polymer allows the selective detection and the quantification of Malaoxon, Methidathion-oxon and Omethoate in such a complex matrix as olive oil without laborious pre-treatment, using small amounts of sample and organic solvents and in a brief time. Additionally, the developed systems present a good analytical performance, with limits of detection much lower than the maximum residue limit tolerated by international regulations. The obtained LODs were as low as $10^{-9} \mathrm{M}$ for the widely used Malaoxon, $10^{-8} \mathrm{M}$ for the Methidathion-oxon and $10^{-7} \mathrm{M}$ for Omethoate. The next step of our research will be the integration of the two systems (extraction and detection) in the same device to detect pesticides directly in olive oil.

\section{Acknowledgements}

Authors acknowledge with gratitude the Averroes programme (EC programme Erasmus Mundus) for granting this work.

\section{References}

[1] Gimeno, E., Fito, M., Lamuela-Raventos, R.M., Castellote, A.I., Covas, M., Farre, M. Europ. Effect of ingestion of virgin olive oil on human low-density lipoprotein composition. J. Clin. Nut. 56, 2002, 114-120.

[2] Lentza-Rizos, Ch. Insecticides authorized for use on olive trees and the relationship between their registration and residues in olive oil. Grasas Aceites. 47, 1996, 392-396.

[3] Lentza-Rizos, C., Avramides, E.J. Pesticide residues in olive oil. Arch. Environ. Contam. Toxicol. 141, 1995, 111-134.

[4] Rastrelli, L., Totaro, K., De Simone, F. Determination of organophosphorus pesticide residues in Cilento (Campania, Italy) virgin olive oil by capillary gas chromatography. Food Chemistry. 79, 2002, 303-305.

[5] Cabras, P., Angioni, A., Garau, V.L., Melis, M., Pirisi, F.M., Karim, M., Minelli, E.V. Persistence of insecticide residues in olives and olive oil. J. Agric. Food. Chem. 45, 1997, 22442247

[6] Guardia-Rubio, M., Marchal-Lopez, R.M., Ayora-Canada, M.J., Ruiz-Medina, A. Determination of pesticides in olives by gas chromatography using different detection systems. J. Chromatogr. A.1145, 2007, 195-203.

[7] Ferrer, C., Gomez, M. J., Garcia-Reyes, J. F., Ferrer, I., Thurman, E. M., Fernandez-Alba, A R. Determination of pesticide residues in olives and olive oil by matrix solid-phase dispersion followed by gas chromatography/mass spectrometry and liquid chromatography/tandem mass spectrometry. J. Chromatogr. A.1069, 2005, 183-194.

[8] Andreescu, S., Barthelmebs, L., Marty, J-L. Anal. Immobilization of acetylcholinesterase on screen-printed electrodes: comparative study between three immobilization methods and applications to the detection of organophosphorus insecticides. Chim. Acta., 464, 2002, 171-180.

[9] Ben Oujji, N., Bakas, I., Istamboulié, G., Ait-Ichou, I., Ait-Addi, E., Rouillon, R., Noguer, T. A Simple Colorimetric Enzymatic-Assay, based on immobilization of acetylcholinesterase by adsorption, for sensitive detection of organophosphorus insecticides in olive oil. Food Control. 46, 2014, 75-80. 
[10] Ben Oujji, N., Bakas, I., Istamboulié, G., Ait-Ichou, I., Ait-Addi, E., Rouillon, R., Noguer, T. Acetylcholinesterase immobilized on magnetic beads for pesticides detection: application to olive oil analysis. Sensors, 12, 2012, 7893-7904.

[11] Ben Oujji, N., Bakas, I., Istamboulié, G., Ait-Ichou, I., Ait-Addi, E., Rouillon, R., Noguer, T. Sol-gel immobilization of acetylcholinesterase for the determination of organophosphate pesticides in olive oil with biosensors. Food Control, 30, 2013, 657-661.

[12] Istamboulie, G., Fournier, D., Marty, J-L., Noguer, T. Phosphotriesterase: A complementary tool for the selective detection of two organophosphate insecticides: Chlorpyrifos and chlorfenvinfos. Talanta. 77, 2009, 1627-1631.

[13] Rhouati, A., Istamboulie, G., Cortina-Puig, M., Marty, J-L., Noguer, T. Selective spectrophotometric detection of insecticides using cholinesterases, phosphotriesterase and chemometric analysis. Enzyme. Microb. Tech., 46, 2010, 212-216.

[14] Istamboulie, G., Cortina-Puig, M., Marty, J-L., Noguer, T. The use of Artificial Neural Networks for the selective detection of two organophosphate insecticides: Chlorpyrifos and chlorfenvinfos. Talanta, 2009, 79, 507-511.

[15] Alonso, G., Istamboulie, G., Ramírez-García, A., Noguer, T., Marty J-L, Munoza, R. Comput. Artificial neural network implementation in single low-cost chip for the detection of insecticides by modelling of screen-printed enzymatic sensors response. Computers and Electronics in Agriculture Electron. Agric. 74, 2010, 223-229.

[16] Lok, C. M. and Son, R. Application of molecularly imprinted polymers in food sample analysis-a perspective. Food Res. Int. $16,2009,127-140$.
[17] Piletsky, S.A., Turner, N.W. and Laitenberger, P. Molecularly imprinted polymers in clinical diagnostics, future potential and existing problems. Med. Eng. Phys. 28, 2006, 971-977.

[18] Bakas, I., Ben Oujji, N., Moczko, E., Istamboulie, G., Piletsky, S., Piletska, E., Ait- Ichou, I., Ait-Addi, E., Noguer, T., Rouillon, R. Molecular imprinting solid phase extraction for selective detection of methidathion in olive oil. Anal. Chim. Acta, 734, 2012, 99-105.

[19] Bakas, I., Ben Oujji, N., Moczko, E., Istamboulie, G., Piletsky, S., Piletska, E., Ait- Ichou, I., Ait-Addi, E., Noguer, T., Rouillon, R. J. Computational and experimental investigation of molecular imprinted polymers for selective extraction of dimethoate and its metabolite omethoate from olive oil. Chromatogr. A. 1274, 2013, 13-18.

[20] Bakas, I., Ben Oujji, N., Istamboulie, G., Piletsky, S., Piletska, E., Ait-Addi, E., Ait-Ichou, I., Noguer, T., Rouillon, R. Molecularly imprinted polymer cartridges coupled to high performance liquid chromatography (HPLC-UV) for simple and rapid analysis of fenthion in olive oil. Talanta. 125, 2014, 313-318

[21] Ellman, G.L., Courtney, K.D., Andres, V., Featherstone, R.M. A new and rapid colorimetric determination of acetylcholinesterase activity. Biochem. Pharmacol. 7 (1961) 88-92.

[22] Hayat, A., Barthelmebs, L., Marty, J.-L. A simple colorimetric enzymatic-assay for okadaic acid detection based on the immobilization of protein phosphatase 2A in sol-gel. Appl. Biochem. Biotech., 2012, 166, 47-56. 